\title{
The Letting Die of the South Asian Body: a Foucauldian Analysis of White Hegemony in Western Cardiovascular Medicine
}

\author{
Rishi Bansal
}

$\mathrm{T}$

HE term "cardiovascular disease" (CVD) refers to a specific and particularly devastating group of diseases that affect the heart and its blood vessels, including coronary heart disease (CHD) and heart failure (HF) (Public Health Agency of Canada). It is the second leading cause of deaths in Canada, and claimed over 51,000 lives in 2016 (Statistics Canada). However, not all ethnic groups are proportionately represented among those with CVD. South Asians (i.e. people from India, Pakistan, Nepal, Sri Lanka, and Bangladesh) have both higher prevalence and higher incidence than other groups (Rana et al. E189).

Navdeep Singh Bedi is an active father of two young children. He does not drink or smoke, is not overweight, and has no apparent family history of CVD. For the average person, these factors would indicate no particular risk of a myocardial infarction (MI) or CHD. Yet in 2009, at age 35, Bedi underwent a double bypass surgery to clear blockage from his coronary arteries. Despite presenting symptoms like shortness of breath, physicians only suspected CHD after multiple visits. Only Bedi's South Asian (SA) ancestry could have tipped them off earlier (Weeks). What is alarming is that Bedi is not alone. There have been numerous cases worldwide that sound eerily similar (Razak and Fernando; O'Connor). In each case doctors were ignorant of the SA CVD risk profile and continuously failed to recognize the signs of CHD until it was almost too late. It is important to clarify that, as Foucault mentions in his Lectures at the Collège de France, the treatment that SAs face is not necessarily due to malicious intent; rather, any observed effects are simply the outcomes of the relationship of power structures to their object (Foucault 28). In this paper, I use a Foucauldian analysis to argue that Bedi's story illustrates a much a larger trend: disciplinary and regulatory mechanisms in medical practice, guidelines, and funding normalize the Caucasian body as 'the body' in Western medical best practices. Individuals and institutions are bound by discursive webs of power that are often unnoticed by the subjects who perpetuate them (Razack et al.). A Foucauldian analysis renders these power relations visible, thereby exposing the norms that make live certain populations while others are let die.

Examining the SA population through a Foucauldian lens begins with the empirical mapping of histories (Foucault 66), which in this case is the heightened CVD risk faced by SAs. The mechanisms of disciplinary power, used to enforce social cohesion through surveillance (33), are made manifest by examining power in its most dilute and regional institutions (27). In each instance, the State fashions itself a series of norms that codifies and stratifies society, making subgroups like SAs legible to power (255). These norms are enacted by doctors and included in guidelines, shored up through claims of "scientificity," subjugating other knowledges that vary from the norm (7-8). In examining how this 'science of subjugation' is funded, the biopolitical control of populations is made apparent through the racist dialogue that thrums beneath the veneer of an "equal" society (245). Thus, the presupposition of the Caucasian body as the norm in medical best practices "makes live" whiteness and "lets die" South Asian populations.

This essay is limited by the scarcity of Canadianfocused primary research in South Asian populations. 
This, in and of itself, is a mark of the indifference of the State toward SAs. As a result, it is necessary to use American research to supplement Canadian literature. Therefore, it is also important to mention the similarities and differences between Canadian and American SA populations. One important similarity is that, regardless of location, the physiology of SAs is unlikely to change based on geography (Anand). Key among the differences is the contrasting policies concerning cultural identity: Canada has a multicultural 'mosaic' policy approach, while the U.S. has an assimilation-based 'Melting Pot' perspective (Peach 7-8). These differences in policy surrounding cultural practices may affect any discussion of topics that are culturally specific, including the cultural sensitivity in treatment plans and patient-physician interactions.

As Foucault does in his lectures, this essay must first empirically map the relations of subjugation; in doing so, the ways in which SAs are manufactured and constituted by their relationship to power comes to light (45). The 2017 Canadian Cardiovascular Society HF guideline outlined many risk factors of CVD including: diabetes, obesity, dyslipidemia, diet, and sedentary behavior (Ezekowitz et al. 1344). Though there is a scarcity of large-scale randomized clinical trials (RCTs) and data pertaining to SAs (Fernando et al. 1139), recent publications have begun to outline the specific physiological ways in which the SA population is particularly susceptible to CVD (Rana et al. E183). The "thrifty gene" hypothesis is a popular genetic theory to explain elevated SA CVD risk; however, research to date is inconclusive regarding broad genetic patterns that might suggest a hereditary predisposition to disease (1144). That being said, most of the increased CVD burden in SAs can be explained by elevated traditional risk factors: and though they are not shored up by genetics, there are still crucially important differences between SAs and other groups. One major risk factor that is highly prevalent within SAs is type 2 diabetes mellitus (T2DM). Patients with T2DM have been shown to have a 2 to 3 times higher risk of cardiovascular death (Volgman et al. e6). Not only do SAs have a 2 to 5 -fold higher prevalence of T2DM than Caucasians or other ethnicities (e6; Fernando et al. 1142), but they also receive diagnoses up to 10 years earlier (Lau 102). This evidence was corroborated in a longitudinal study conducted between 2001 and 2012 in Ontario, Canada (Chiu et al. 2), and was paralleled in South Asian immigrants to Canada (Banerjee and Shah 2).

T2DM is also related to metabolic syndrome (MetS), which is a cluster of insulin resistance-linked factors including obesity and dyslipidemia. Obesity is usually measured using Body Mass Index (BMI), with a diagnostic cutoff of $\geq 25 \mathrm{~kg} / \mathrm{m}^{2}$ (Araneta et al. 814). However, this cutoff is inappropriate for SA populations, who have been shown to develop risk factors and metabolic abnormalities at BMIs as low as $21.0 \mathrm{~kg} / \mathrm{m}^{2}$, which compares to a BMI of $30 \mathrm{~kg} / \mathrm{m}^{2}$ in Caucasians. (Fernando et al. 1143). Furthermore, due to higher body fat percentages and abdominal fat retention, the association between BMI and CVD risk could be underestimated (Volgman et al. e6; Fernando et al. 1143). Thus, current screening standards for BMI both overlook many at-risk SA patients and underestimate CVD risk at each BMI level. Dyslipidemia is another important risk factor, characterized by abnormal cholesterol and triglyceride levels in the blood (Volgman et al. e7). SAs have consistently been shown to have low high-density lipoprotein (HDL) cholesterol, elevated low-density lipoprotein (LDL) cholesterol, hypertriglyceridemia (higher concentration of blood triglycerides), all of which could be pathophysiologically linked with insulin resistance and MetS (Fernando et al. 1143).

Finally, two modifiable, but important, risk factors in SAs are diet and sedentary behaviour. The SA diet is typically higher in carbohydrates and saturated fats, which are both associated with higher risk of dyslipidemia (Rana et al. E183). SAs are also less active than other groups (E183). This could account for up to $20 \%$ of the excess CHD risk in SAs, potentially through heightened risk for obesity and T2DM (Fernando et al. 1144). Ultimately, medical research to date has provided strong evidence to support a unique CVD risk profile for SAs. This suggests that 'equal' treatment of all ethnic groups may not be equitable, and providing the same drug and lifestyle interventions may actually cause harm. It is clear that in order for the SA body to live and thrive, the development of patient-focused and culturally sensitive interventions is necessary.

An ascending Foucauldian analysis of power begins in the capillaries. By examining power in its "most regional forms and institutions," it is possible to discern where broader power intervenes in the lives of citizens (Foucault 27). In these regional in- 
stitutions, power is expressed through "mechanisms of disciplinary coercion," exercised through "constant surveillance" that enforces the cohesion of the social body $(37 ; 33)$. To clarify, the executors of power are not interested in the objects of their subjugation, but rather in the mechanisms of exclusion and any economic or political profit reaped thereof (33). These mechanisms set up the precondition of racism and differential treatment that "makes killing acceptable" (256). In medicine, the most capillary institutions of power are the clinics, where patients, primary care physicians, and specialists interact daily. In these spaces, doctors are the conduits for disciplinary power, and individuals are subject to intense scrutiny. Using medicalized knowledge to connect symptoms to disease states, doctors constitute their patients by their deviation from the mean "healthy body." In an effort to "rehabilitate" the body back towards the norm of productivity, they assign treatments to resolve these variances (33). However, patients are also constituted by each other-physician interactions with Caucasian patients provide them with a 'baseline' against which they can compare their ethnic patients (Johnson et al. 263). Hence, through othering narratives and implicit bias, SA patients are further constituted not by their identity as an individual patient, but through their differences from Caucasian patients (263).

In a study done on care providers' discussions about SA patients, these narratives were glaringly apparent and highly prevalent across providers (Johnson et al. 259). The racist practices were "radically heterogeneous" in their execution (Foucault 26), but commonly utilized language that distinguished "them [South Asians]" from "us [Caucasians]," and enabled the separation of SAs as a group (Johnson et al. 259 ; 263). For example, clinicians made particular reference to Caucasians as the compliant "idealized patient" who fit their clinical expectations (263), and made condescending and racialized assumptions about their non-ideal (i.e. SA) patients (264). These prejudices can lead to very real actions: providers have been shown to spend more time learning about the needs of Caucasian patients while ethnic minorities are pushed aside (Hall et al. e61). Worse, the ignorance of physicians regarding the unique SA CVD risk profile puts patients at risk and diverts them from care: physician use of BMI in SA risk assessment means that some patients are overlooked (Araneta et al. 814); implicit biases result in lower cardiac rehabilitation recommendation rates (Mochari et al. 10 ); and the lack of culturally sensitive cardiac rehabilitation programs present a barrier to SA access and adherence to treatment (Banerjee et al. 21516). As a direct result, the Caucasian population reaps the "economic profit" produced by these disciplinary mechanisms (Foucault 33). Not only do they receive more comprehensive treatment (as a function of increased facetime), but in a health system that is resource-strapped, every time a SA is diverted from care, those resources are necessarily given to another. In this way, the healthcare system also has a racist effect in that it has determined that Caucasian bodies are to be made live and South Asian bodies are to be let die. This serves to "justif[y] the death-function" of biopower - it appeals to the principle that, given finite resources, the death of SA patients means better prospects for others (258).

While disciplinary power operates on the level of man-as-body, other power mechanisms are needed to control the general population (Foucault 242). This new phenomenon, "biopower," introduced mechanisms, including forecasts and statistics, that controlled the biological processes of man-as-species rather than identifying and modifying individuals (247). These functions intervened at the broadest level to influence the generality of population statistics by promoting certain norms of bodily conduct (246). Importantly, they attempted to establish an "average" for the population, compensating for the natural variation within the State in order to "optimize a state of life" and achieve social control (246). Thus, these functions make claims to universality while they are, in fact, particular (65). Yet, these claims to generality are the main expression of power, shored up through claims to scientificity (7). Medicine, in particular, has a stake in proclaiming its "scientificity," casting aside other knowledges that do not fit the norm through so-called 'justified principles' (7). The localized knowledge of the patient or the doctor are dismissed as "insufficiently elaborated" and become subjugated (8). The life of medicine as a discipline is in claiming these generalities, and moreover, claiming their application to localized instances. Medical school trains doctors in these medical generalizations; clinical practice guidelines (CPGs) provide 'gold standard' and 'evidencebased' generalized recommendations for practitioners 
(Canadian Cardiovascular Society).

Despite established risk factors, there is a paucity of SA-specific recommendations in Canadian heart CPGs. The guidelines for ischemic heart disease, systematizing inpatient referrals to cardiac rehabilitation, and pulmonary arterial hypertension make no mention of any differences for SA populations (Mancini et al.; Grace et al.; Langleben et al.). The 2016 update for lipid CPGs include a consideration for earlier screening in SAs, though the recommended screening methods are "not validated for South Asian[s]," (Anderson et al. 1266; 1265). These findings are startling, especially considering the wealth of recent reviews and studies that support a distinct SA risk profile. An explanation can be found by examining the evidence that CPGs are founded on. CPGs are themselves robust reviews of the literature and provide recommendations with varying degrees of confidence (Canadian Cardiovascular Society). The gold standard sources of evidence for strong recommendations are large, multicenter RCTs. However, as previously indicated, there is a lack of large-scale RCTs for SA populations (Fernando et al. 1139). As a result, findings from smaller studies become subjugated, as they do not provide high enough quality evidence; they are "below the required level of erudition" (Foucault 6). This dearth can be partially explained due to a lack of funding. RCTs are expensive to run, and researchers rely on government grants for capital - it is here where racism intervenes. In choosing what research is to be provided with a grant, government agencies determine which bodies are worth studying, creating caesuras among the biological continuum (255). This is how the medicalized "letting die" of SAs begins, with the relative indifference of the medical field to the increased CVD burden in SAs.

A U.S.-based article documented systemic racism in healthcare, showing that powerful decision-makers have historically been white, a pattern that persists today (Feagin and Bennefield 8). Research-funding institutions are racialized and largely white-oriented; as a direct result, research efforts to investigate health disparities are largely underfunded (9). These trends are also highly prevalent in Canada. For example, Dr. Sonia Anand is a world-renowned researcher in Ethnic Diversity and CVD. Yet when she began her research more than 20 years ago, it took multiple grant applications to receive funding to study CVD in SAs. At the time, the government agency peer review committee was hesitant to provide funding to research SAs, who were deemed to be "not as important" as other research in mainstream Canadians (Anand). In other words, the agency was unwilling to fund research for non-white bodies.

Though there have been recent efforts to document the CVD burden in SAs (e.g. the MASALA study), these RCTs are still in their infancy and are located in the U.S. (Volgman et al. e5). Hence, guidelines are forced to utilize previously published RCTs, where South Asians are underrepresented among study cohorts (Quay et al. 1). It is important to note that some of the relevant barriers included cultural insensitivity, a lack of effort on the behalf of researchers to recruit diverse cohorts, and researcher bias (8). A UK study noted that affable patients are often "cherry picked," for research (Hussain-Gambles et al. 157). Most often, these "idealized patients" are also Caucasian (Johnson et al. 263; Anand). While this study was conducted in the UK, it is likely that these attitudes are also present in Canada (Anand). Hence, CPGs based on these RCTs act much like the unjust kings of Roman history: they are partisan, but they speak as if they are not (Foucault 72). The recommendations do not, in fact, apply to all populations, for they are based on research conducted upon the white man's body. Recently, efforts have been made to rectify this issue and improve diversity in both cardiovascular clinical trials and medicine as a whole (Ortega et al.). Yet underrepresentation of people of color, women, and other traditionally marginalized groups remains a persistent issue (Grumbach and Mendoza). These efforts are necessary, and must be intensified to achieve better diversity in the future, but there is significant work that remains before we achieve that goal. Fundamentally, biopower has intervened on the level of population dynamics, and has contributed to the creation of a normalized society, which is the "precondition" to the letting die of those outside the norm (Foucault 256). In this way, the 'white body' became 'the body' in medical practice, and the roots of these generalities have long since been forgotten.

It is also important to comment on how this essay fits into a much broader context. Examining these power relations and making their effects legible is, in itself, a form of race struggle. Consequently, this essay also contains a counterhistorical function (Fou- 
cault 66 ). In this essay, I have attempted to act as a historian and cartographer, mapping the rituals of power and how SAs are constituted by power (67). This essay delineates the race struggle against white hegemony in medicine, situated in a counterhistory that was long-hidden in the "darkness and silence" of subjugation (70). However, this essay is not only a documentation or critique - it is also an "attack" on power, and a "demand" (73). Within this essay is a call to recognize the increased CVD burden in SAs, and moreover, a call for a healthcare system that is better equipped to treat the SA population. Finally, it is important to recognize that while this essay is specific to SAs, the medicalized letting die of bodies is not. The biopolitical mechanisms in society may operate in similar fashion for other groups, such as those defined by the isms (e.g. women, indigenous peoples). Moreover, many members of the SA population may possess intersectional identities that contribute to unique forms of discrimination beyond those documented in this essay. While this essay was limited in scope to the ethnic identity of SAs, these other aspects of identity are equally important. These groups also demand recognition, especially in the juridical form of the State (222).

Navdeep Bedi Singh's case was tragic, but, luckily, he recovered from his surgery. Many others are not as lucky. Bedi's case ultimately delineates the larger issue of white hegemony in medicine. Though it is clear that SAs pose a unique risk profile compared to Caucasians, this is not recognized by healthcare professionals. Rather, they utilize their own presuppositions to prejudicially [mis]treat SAs. While physicians' actions are rarely intentional, the consequences are nonetheless real and highly prevalent. CPGs dismiss existing literature about SAs as insufficiently erudite, and normalize population recommendations based on research conducted with primarily Caucasian cohorts. Ultimately, these power relationships are structured and sponsored by the State when its agencies decide which bodies are worthy of study. These effects are not mutually exclusive; in fact, they amplify each other and intensify the making live of whiteness, and the letting die of SAs. Yet essays like this one aspire to have a counterhistorical function, and demand recognition of the SA body. As such, it is my hope that by contributing to the larger discourse and rendering the SA counterhistory visible, that this change will be forthcoming as the medical community strides forward into the future.

\section{Acknowledgements}

The author would like to acknowledge Dr. David L Clark, Ms. Danielle Martak, and Dr. Sonia Anand for their support and feedback.

\section{Author Biography}

Rishi Bansal graduated from the Arts \& Science program at McMaster University, and will be entering the Michael G. DeGroote School of Medicine Class of 2023 this August. He is also a research student at both St. Michael's Hospital and McMaster. As a person of South Asian ancestry, Rishi was interested to see what research had been done to examine the excessive risk cardiovascular faced by members of his ethnicity, but found a shocking paucity of studies. This essay documents his examination of the underlying power structures that have precipitated this situation. Rishi's other interests include health leadership, systems innovation, and digital health. You can engage with him and his other work via Twitter "@rishibansal_". 


\section{Works Cited}

Anand, Sonia. Personal Interview. 1 Apr. 2019.

Anderson, Todd J., et al. "2016 Canadian Cardiovascular Society Guidelines for the Management of Dyslipidemia for the Prevention of Cardiovascular Disease in the Adult." Canadian Journal of Cardiology, vol. 32, no. 11, Nov. 2016, pp. 1263-82. www.onlinecjc.ca, doi:10.1016/j.cjca.2016.07.510.

Araneta, Maria Rosario G., et al. "Optimum BMI Cut Points to Screen Asian Americans for Type 2 Diabetes." Diabetes Care, vol. 38, no. 5, May 2015, pp. 814-20. PubMed Central, doi:10.2337/dc142071.

Banerjee, A. T., and B. R. Shah. "Differences in Prevalence of Diabetes among Immigrants to Canada from South Asian Countries." Diabetic Medicine, vol. 35, no. 7, 2018, pp. 937-43. Wiley Online Library, doi:10.1111/dme.13647.

Banerjee, Ananya Tina, et al. "Patient Characteristics, Compliance, and Exercise Outcomes of South Asians Enrolled in Cardiac Rehabilitation." Journal of Cardiopulmonary Rehabilitation and Prevention, vol. 27, no. 4, Aug. 2007, p. 212. journals.lww.com, doi:10.1097/01.HCR.0000281765.52158.be.

Canadian Cardiovascular Society. "About Guidelines." Canadian Cardiovascular Society, 2018, https://www.ccs.ca/en/guidelines.

Chiu, Maria, Peter C. Austin, et al. "Cardiovascular Risk Factor Profiles of Recent Immigrants vs LongTerm Residents of Ontario: A Multi-Ethnic Study." Canadian Journal of Cardiology, vol. 28, no. 1, Jan. 2012, pp. 20-26. ScienceDirect, doi:10.1016/j.cjca.2011.06.002.

Chiu, Maria, Laura C. Maclagan, et al.. "Temporal Trends in Cardiovascular Disease Risk Factors among White, South Asian, Chinese and Black Groups in Ontario, Canada, 2001 to 2012: A PopulationBased Study." BMJ Open, vol. 5, no. 8, Aug. 2015, p. e007232. bmjopen.bmj.com, doi:10.1136/bmjopen-2014-007232.

Ezekowitz, Justin A., et al. "2017 Comprehensive Update of the Canadian Cardiovascular Society Guidelines for the Management of Heart Failure." Canadian Journal of Cardiology, vol. 33, no. 11, Nov. 2017, pp. 1342-433. Crossref, doi:10.1016/j.cjca.2017.08.022.

Feagin, Joe, and Zinobia Bennefield. "Systemic Racism and U.S. Health Care." Social Science Es Medicine, vol. 103, Feb. 2014, pp. 7-14. ScienceDirect, doi:10.1016/j.socscimed.2013.09.006.

Fernando, Eshan, et al.. "Cardiovascular Disease in South Asian Migrants." Canadian Journal of Cardiology, vol. 31, no. 9, Sept. 2015, pp. 1139-50. Crossref, doi:10.1016/j.cjca.2015.06.008.

Foucault, M. Society Must Be Defended: Lectures at the Collège de France 1975-76. Edited by Maurio Bertani, François Edwald, and Alessandro Fontana. Translated by David Macey. St. Martin's Press, 2003, Picador, New York.

Government of Canada, Statistics Canada. Leading Causes of Death, Total Population, by Age Group. 27 June 2018, https://www150.statcan.gc.ca/t1/tbl1/en/tv.action?pid=1310039401. 
Grace, Sherry L., et al.. "Systematizing Inpatient Referral to Cardiac Rehabilitation 2010: Canadian Association of Cardiac Rehabilitation and Canadian Cardiovascular Society Joint Position Paper: Endorsed by the Cardiac Care Network of Ontario." Canadian Journal of Cardiology, vol. 27, no. 2, Mar. 2011, pp. 192-99. www.onlinecjc.ca, doi:10.1016/j.cjca.2010.12.007.

Grumbach, Kevin, and Rosalia Mendoza. "Disparities In Human Resources: Addressing The Lack Of Diversity In The Health Professions." Health Affairs, vol. 27, no. 2, Health Affairs, Mar. 2008, pp. 413-22. healthaffairs.org (Atypon), doi:10.1377/hlthaff.27.2.413.

Hall, William J., et al. "Implicit Racial/Ethnic Bias Among Health Care Professionals and Its Influence on Health Care Outcomes: A Systematic Review." American Journal of Public Health, vol. 105, no. 12, Dec. 2015, pp. e60-76. PubMed Central, doi:10.2105/AJPH.2015.302903.

Hussain-Gambles, Mah, et al. "South Asian Participation in Clinical Trials: The Views of Lay People and Health Professionals." Health Policy, vol. 77, no. 2, July 2006, pp. 149-65. ScienceDirect, doi:10.1016/j.healthpol.2005.07.022.

Johnson, Joy L., et al.. "Othering and Being Othered in the Context of Health Care Services." Health Communication, vol. 16, no. 2, Apr. 2004, pp. 255-71. Taylor and Francis+NEJM, doi:10.1207/S15327027HC1602_7.

Langleben, David, et al. "Canadian Cardiovascular Society and Canadian Thoracic Society Position Statement on Pulmonary Arterial Hypertension." Canadian Respiratory Journal, vol. 12, no. 6, 2005, pp. 303-15. Crossref, doi:10.1155/2005/156750.

Lau, David C. W. "Excess Prevalence Mortality Rates of Diabetes Cardiovascular Disease Among South Asians: A Call to Action." Canadian Journal of Diabetes, vol. 34, no. 2, Jan. 2010, pp. 102-04. www.canadianjournalofdiabetes.com, doi:10.1016/S1499-2671(10)42004-3.

Mancini, G. B. John, et al. "Canadian Cardiovascular Society Guidelines for the Diagnosis and Management of Stable Ischemic Heart Disease." Canadian Journal of Cardiology, vol. 30, no. 8, Aug. 2014, pp. 837-49. www.onlinecjc.ca, doi:10.1016/j.cjca.2014.05.013.

Mochari, Heidi, et al. "Ethnic Differences in Barriers and Referral to Cardiac Rehabilitation Among Women Hospitalized With Coronary Heart Disease." Preventive Cardiology, vol. 9, no. 1, 2006, pp. 8-13. Wiley Online Library, doi:10.1111/j.1520-037X.2005.3703.x.

O'Connor, Anahad. "Why Do South Asians Have Such High Rates of Heart Disease?" The New York Times, 12 Feb. 2019. NYTimes.com, https://www.nytimes.com/2019/02/12/well/live/why-dosouth-asians-have-such-high-rates-of-heart-disease.html.

Ortega Rebecca F., et al. "Overcoming Lack of Diversity in Cardiovascular Clinical Trials." Circulation, vol. 140, no. 21, American Heart Association, Nov. 2019, pp. 1690-92. ahajournals.org (Atypon), doi:10.1161/CIRCULATIONAHA.119.041728.

Peach, Ceri. "The Mosaic versus the Melting Pot: Canada and the USA." Scottish Geographical Journal, vol. 121, no. 1, Jan. 2005, pp. 3-27. Taylor and Francis+NEJM, doi:10.1080/00369220518737218.

Public Health Agency of Canada. "Heart Disease in Canada." Government of Canada, 10 Feb. 2017, 
https://www.canada.ca/en/public-health/services/publications/diseases-conditions/heart-disease-canada.html.

Quay, Teo AW, et al. "Barriers and Facilitators to Recruitment of South Asians to Health Research: A Scoping Review." BMJ Open, vol. 7, no. 5, May 2017, p. e014889. bmjopen.bmj.com, doi:10.1136/bmjopen2016-014889.

Rana, Ayesha, et al. "Cardiovascular Risk among South Asians Living in Canada: A Systematic Review and Meta-Analysis." CMAJ Open, vol. 2, no. 3, July 2014, pp. E183-91. cmajopen.ca, doi:10.9778/cmajo.20130064.

Razak, Fahad, and Eshan Fernando. "If You're South Asian, Take Steps Now to Prevent a Heart Attack." The Toronto Star, 29 Feb. 2016, https://www.thestar.com/life/health_wellness/2016/02/29/if-youresouth-asian-take-steps-now-to-prevent-a-heart-attack.html.

Razack, Saleem, et al. "The More It Changes; the More It Remains the Same: A Foucauldian Analysis of Canadian Policy Documents Relevant to Student Selection for Medical School." Advances in Health Sciences Education, vol. 19, no. 2, May 2014, pp. 161-81. Springer Link, doi:10.1007/s10459-0139468-2.

Saha, Somnath, et al. "Patient-Physician Relationships and Racial Disparities in the Quality of Health Care." American Journal of Public Health, vol. 93, no. 10, Oct. 2003, pp. 1713-19. ajph.aphapublications.org (Atypon), doi:10.2105/AJPH.93.10.1713.

Schulman, Kevin A., et al. "The Effect of Race and Sex on Physicians' Recommendations for Cardiac Catheterization." Http://Dx.Doi.Org/10.1056/NEJM199902253400806, 21 Oct. 2008, doi:10.1056/NEJM199902253400806.

Veenstra, Gerry, and Andrew C. Patterson. "South Asian-White Health Inequalities in Canada: Intersections with Gender and Immigrant Status." Ethnicity \& Health, vol. 21, no. 6, Nov. 2016, pp. 639-48. Taylor and Francis+NEJM, doi:10.1080/13557858.2016.1179725.

Volgman, Annabelle Santos, et al. "Atherosclerotic Cardiovascular Disease in South Asians in the United States: Epidemiology, Risk Factors, and Treatments: A Scientific Statement From the American Heart Association." Circulation, vol. 138, no. 1, July 2018, pp. e1-34. ahajournals.org (Atypon), doi:10.1161/CIR.0000000000000580.

Weeks, Carly. "The South Asian Enigma: Early Risk of Heart Disease." The Globe and Mail, 23 Dec. 2009. The Globe and Mail, https://www.theglobeandmail.com/life/health-and-fitness/the-southasian-enigma-early-risk-of-heart-disease/article572553/. 